\title{
Sjögren's Syndrome and MALT Lymphomas of Salivary Glands: A DNA-Cytometric and Interphase-Cytogenetic Study
}

Stephan Ihrler, M.D., Gustavo B. Baretton, M.D., Ph.D., Frank Menauer, M.D., Sabine Blasenbreu-Vogt, M.D., Udo Löhrs, M.D., Ph.D.

Institute of Pathology (SI, GBB, SB, UL) and Department of ENT, Head and Neck Surgery (FM), Ludwig Maximilians University, München, Germany

Few and conflicting cytogenetic data are available concerning the chromosomal constitution of (mainly gastric) extranodal marginal zone B-cell non-Hodgkin's lymphoma arising from mucosaassociated lymphoid tissue (MALT)-type lymphoma. The majority of salivary gland MALT lymphomas are thought to develop from longstanding Sjögren's syndrome/benign lymphoepithelial lesion (BLEL). We tried to achieve a better comprehension of related cytogenetic alterations by comparing DNA-ploidy and numerical chromosomal (\#) aberrations, assessed by different techniques of DNA cytometry (image cytometry) and interphase cytogenetics using nonradiographic in situ hybridization (centromere specific probes for $\# 3,7,12,18$ ) on 12 cases of BLEL, 13 low-grade MALT lymphomas (LG-MALT-L) and 4 high-grade MALT lymphomas (HG-MALT-L) of salivary gland. Both techniques were applied on tissue sections preferentially, enabling a reliable measurement of histomorphologically identified areas. No case of BLEL showed cytogenetic abnormalities. Three of 4 HG- and 2 of 13 LG-MALT-L exhibited complex chromosomal gains in nonisotopic in situ hybridization, which were reflected by DNA nondiploidy in image cytometry. In 6 of 13 LG- and 10 4 HG-MALT-L, one or two numerical chromosomal aberrations were demonstrated by nonisotopic in situ hybridization, which could not be resolved by image cytometry. In the 11 DNA-diploid LG-MALT-L, trisomies 18, 3, and 12 were found in 36,12 , and $9 \%$, respectively. In conclusion, comparing BLEL, which showed no chromosomal aberrations, with LG- and HG-MALT-L, an

Copyright () 2000 by The United States and Canadian Academy of Pathology, Inc.

VOL. 13, NO. 1, P. 4, 2000 Printed in the U.S.A

Date of acceptance: August 3, 1999.

Address reprint requests to: Stephan Ihrler, M.D., Institute of Pathology, Ludwig Maximilians University, München, Germany, Thalkirchnerstraße 36, D-80337 München, Germany; e-mail: Stephan.Ihrler@Irz.unimuenchen.de; fax: 49-89-5160-4043. increase in frequency and number of numerical aberrations and DNA nondiploidy was seen. Peritetraploid DNA nondiploidy might be characteristic for HG-MALT-L of salivary gland as it is a rare finding in MALT lymphomas of other sites. It is unclear whether the documented chromosomal aberrations in LG-MALT-L, especially increased rate of trisomy 18 , indicate a pathogenic impact or merely reflect genetic instability.

KEY WORDS: DNA cytometry, Extranodal lymphoma, Interphase cytogenetics, Mucosaassociated lymphoid tissue lymphoma, Salivary gland, Sjögren's syndrome.

Mod Pathol 2000;13(1):4-12

Non-Hodgkin's lymphomas (NHLs) account for approximately $3 \%$ of all tumors of major salivary glands (1). Most of these cases are mucosaassociated lymphoid tissue (MALT)-type lymphomas of primary salivary gland origin according to the concept of MALT, introduced by Isaacson (2). These lymphomas recently were classified as extranodal marginal zone B-cell lymphomas by the revised European-American classification of lymphoid neoplasms (REAL) (3). A secondary infiltration of glandular parenchyma and/or of intraglandular lymph nodes by primary nodal NHL, however, has to be considered as well. This differentiation is important, because MALT lymphomas in general have an indolent clinical course with a propensity to remain localized to the primary site for a long period of time as a result of epitheliotropism and a restricted homing pattern (4-7). Because they often respond favorably to local therapy, prognosis generally is considerably better than for nodal-type NHL $(1,8)$.

Most salivary gland MALT lymphomas are thought to develop on the basis of chronic antigenic stimulation of Sjögren's syndrome/benign lymphoepithelial lesion (BLEL) $(4,5,8-10)$. In re- 
cent studies, we showed that the characteristic duct lesions develop through a basal cell hyperplasia of striated ducts with a distinct "lymphoepithelial metaplasia" $(11,12)$. In parallel, the often postulated participation of myoepithelial cells was excluded. This kind of lymphoepithelial lesion, being a diagnostic hallmark for reactive BLEL, is different from gastric lymphoepithelial lesion, which is regarded as diagnostic for low-grade MALT lymphomas (LG-MALT-L) of the stomach $(2,13-15)$. Transition of BLEL into LG-MALT-L is diagnosed in cases with intense periductal expansion of centrocyte-like or monocytoid marginal zone B-lymphocytes (so-called "halos"), whereas follicu- lar colonization of reactive germinal centers is usually characteristic of more advanced lesions (Fig. 1a) (4, 7-9). Lymphoma diagnosis, furthermore, can be supported by an aberrant B-cell immunophenotype and immunohistochemical evidence of immunoglobulin light chain restriction. Molecular biologic studies on respective clonal gene rearrangement of the immunoglobulin light chains, conversely, are only of limited value, as it has been documented repeatedly in up to $42 \%$ of BLEL cases as well (1416). High-grade MALT lymphomas (HG-MALT-L) of salivary gland are rare; they are believed to develop either secondarily from LG-MALT-L or de novo (3, $5,15)$.

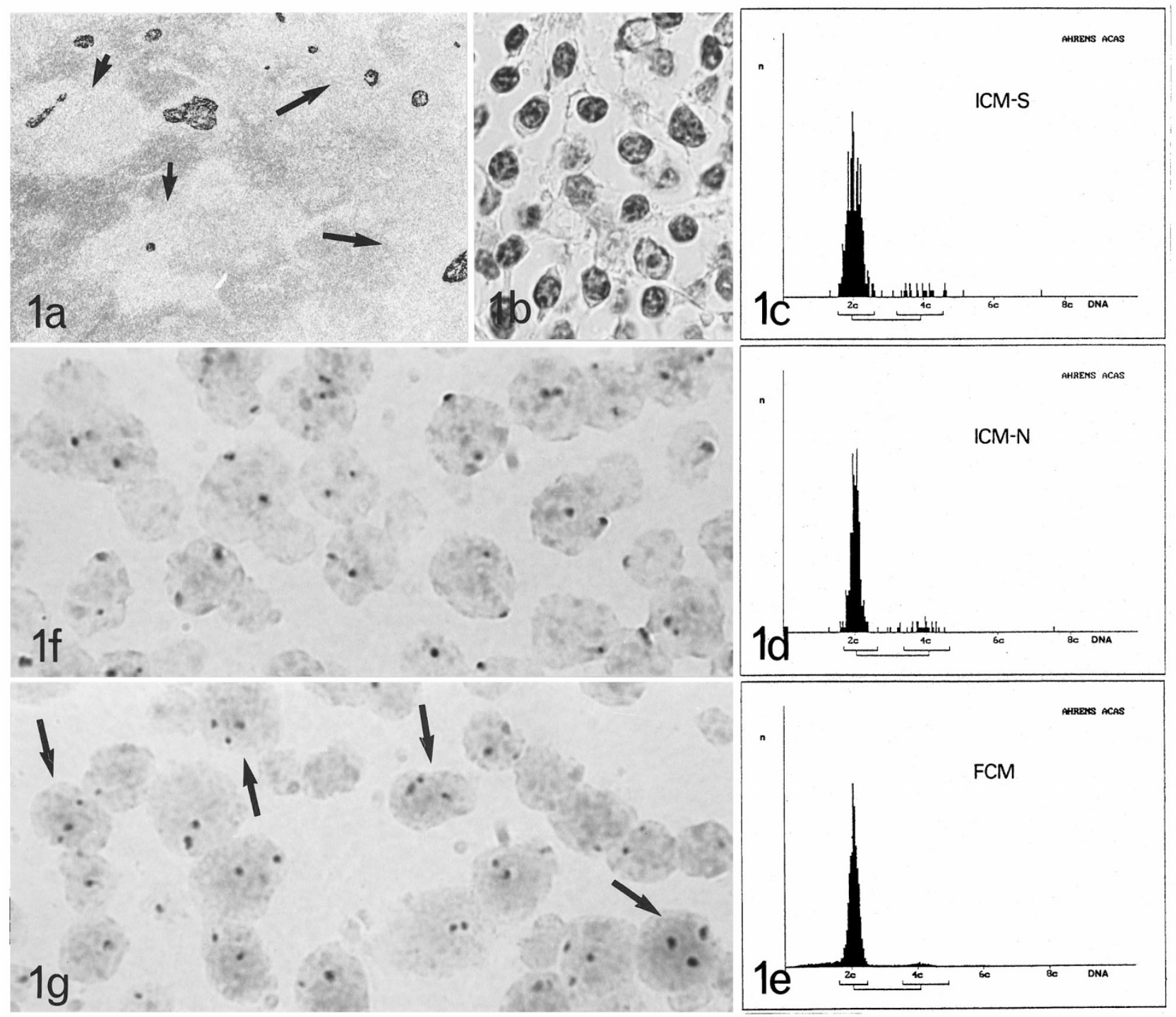

FIGURE 1. Low-grade mucosa-associated lymphoid tissue-type lymphoma (LG-MALT-L) (Case 13). a, in a pan-keratin stain, lymphoepithelial duct lesions advocate preexisting benign lymphoepithelial lesion. Transition into LG-MALT-L is indicated by intense marginal zone-type periductal expansion (small arrows) and confluence (large arrows; original magnification, $34 \times$ ) of centrocyte-like neoplastic B-lymphocytes, highlighted in a Feulgen-stained section (b; original magnification, $450 \times$ ). c, d, e, corresponding DNA histograms show DNA diploidy in image cytometry of tissue section (ICM-S; $\mathrm{CV}_{\text {diploid }}, 6.6 \%$ ) (c), in image cytometry of cell suspension (ICM-N; $\mathrm{CV}_{\text {diploid }}, 5.9 \%$ ) (d), and in flow cytometry (FCM; CV (e). f, nonradiographic in situ hybridization of tissue section using a centromere-specific probe for chromosome 7 exhibits two copies in the majority of nuclei within histomorphologically identified lymphoma areas (original magnification, $1200 \times$ ). However, trisomy 18 is diagnosed with gain of an additional third copy number in more than 15\% of nuclei (g; arrows; original magnification, $1200 \times$ ). 
On the basis of the hypothesis that most MALT lymphomas of salivary glands develop from BLEL, the goal of our study was to gain insight into the genetic alterations during this poorly understood transition. Most cytogenetic data on MALT lymphomas were derived from gastric tumors, because the stomach is by far the most common site (16-23) (Table 1). There are no data on DNA ploidy in salivary gland MALT lymphomas as yet, and conventional and interphase cytogenetics applied to either fresh tumor specimens or cell suspensions of paraffin material have rendered only scant and conflicting information regarding chromosomal aberrations $(16,17,19,24)$. To the best of our knowledge, no study has combined DNA cytometric determination of the total nuclear DNA content and evaluation of specific chromosomal aberrations (8, $11,18,20)$, assessed by interphase cytogenetics in cases of BLEL and LG- and HG-MALT-L of salivary gland. Both techniques were applied on paraffin sections preferentially, because a reliable measurement of histomorphologically identified lymphoma areas was a central aim of our study.

\section{MATERIALS AND METHODS}

\section{Patients and Tumors}

Formalin-fixed, paraffin-embedded archival material (24 parotid, 4 submandibular, 1 lacrimal gland) from the Institute of Pathology at the University of Munich from 27 patients was studied (1983 to 1998); in 1 patient, two follow-up biopsies were available. All cases were revised according to histomorphologic criteria, including immunohistochemistry (CD3, CD20, CD 68, Bcl-2, MIB1/Ki67, pan-keratin, antibodies against immunoglobulin light chains), as suggested by Isaacson (2) and Quintana et al. (15). In summary, LG-MALT-L was diagnosed in cases with broad, halo-like periductal and confluent sheets of monocytoid or centrocytelike lymphocytes (Figs. 1a, b) demonstrating an aberrant B-cell phenotype, $\mathrm{Bcl}-2$ positivity, and immunohistochemical restriction of immunoglobulin light chains (Fig. 1b). Follicular colonization is a late phenomenon and, hence, was not mandatory for lymphoma diagnosis. HG-MALT-L was diagnosed in cases with large confluent sheets of blasts with high mitotic index or proliferative activity in Ki67 staining, respectively (Fig. 2b). To further rule out specimens with secondary infiltration by nodal NHL, according to Isaacson (2), only cases with limited stage IE/IIE disease but no cases with generalized lymphomas (IIIE/IVE) were included. In three cases, the diagnosis of LG-MALT-L had been confirmed by external reference pathology. Altogether, the collective comprised 12 cases with BLEL and 13 LG- and 4 HG-MALT-L. The mean age ( \pm standard deviation) of the patients was 61.1 $( \pm 11.7)$ for BLEL, $62.5( \pm 13.2)$ for LG-MALT-L, and $73.0( \pm 3.2)$ for HG-MALT-L; the female/male ratio was 5:1 (Table 2). Duct lesions were present in 11 of 12 cases of BLEL and, as an indication of residual BLEL, in 10 of 13 LG- and 2 of 4 HG-MALT-L. Clinical and laboratory data implying Sjögren's syndrome (oral/conjunctival sicca syndrome, ANAand/or SS-A/B antibodies, associated autoimmune diseases) were found in 9 of 12 cases of BLEL and 8 of 13 LG- and 2 of 4 HG-MALT-L. In five cases of lymphoma, magnetic resonance imaging scans were available, each demonstrating radiologic features favoring a primary salivary gland MALT lymphoma, as described earlier by our group (6) (Fig. 2a). Follow-up data were not available for 5 of 12 patients with BLEL and for 6 of 15 patients with lymphoma. In the other cases, clinical information

TABLE 1. Cytogenetic Investigations on MALT Lymphomas

\begin{tabular}{|c|c|c|c|c|}
\hline Studies & Applied technique & No. & LG/HG & Prevalent cytogenetic findings \\
\hline \multicolumn{5}{|c|}{ Salivary gland MALT lymphomas } \\
\hline Auer et al. (24) & conventional cytogenetics & 3 & LG & trisomies 3,18 in 1 case, complex \# gain in 1 case \\
\hline Ott et al. (16) & conventional cytogenetics & 8 & LG/HG & $\begin{array}{l}\text { trisomy } 18 \text { in } 1 \text { of } 4 \text { LG cases } \\
\text { complex \# gain in } 2 \text { of } 4 \text { HG cases }\end{array}$ \\
\hline Whang-Peng et al. (23) & conventional cytogenetics & 1 & LG & trisomies $3,12,18$ \\
\hline Wotherspoon et al. (17) & NISH (cell suspension) & 11 & LG & trisomy 3 in $82 \%$, trisomy 18 in $18 \%$ \\
\hline Present study & $\begin{array}{l}\text { DNA cytometry and NISH } \\
\text { (tissue section) }\end{array}$ & 17 & LG/HG & $\begin{array}{l}\text { trisomies } 18,3,12 \text { in } 36,12,9 \% \text { in } \mathrm{LG} \text { cases, } \\
\text { peritetraploid DNA nondiploidy in } 3 \text { of } 4 \text { HG cases }\end{array}$ \\
\hline \multicolumn{5}{|c|}{ MALT lymphomas of all locations, especially gastrointestinal } \\
\hline Barth et al. (22) & CGH & 31 & HG & overrepresentation of all or part of $\# 12,11$ in $29,19 \%$ \\
\hline Chan et al. (21) & CGH and FISH & 15 & HG & trisomy 12 in 11 of 15 cases \\
\hline Dierlamm et al. (31) & $\begin{array}{l}\text { conventional cytogenetics/ } \\
\text { FISH (cell suspension) }\end{array}$ & 36 & LG & trisomy 3 in $61 \%$; complex \# gain in 2 of 22 cases \\
\hline Ott et al. (19) & FISH (cell suspension) & 105 & LG/HG & $\begin{array}{l}\text { trisomies } 3,7,12,18 \text { in } 20,3,3,7 \% \text { in LG cases; } \\
\quad \text { trisomies } 3,7,12,18 \text { in } 31,27,23,8 \% \text { in HG cases }\end{array}$ \\
\hline Ott et al. (16) & conventional cytogenetics & 44 & LG/HG & $\begin{array}{l}\mathrm{t}(11 ; 18)(\mathrm{q} 21 ; \mathrm{q} 21) \text { in } 7 \text { of } 20 \mathrm{LG} \text { cases, trisomy } 3 \text { in } 2 \\
\text { of } 20 \mathrm{LG} \text { cases, complex \# gain in } 3 \text { of } 24 \mathrm{HG} \text { cases }\end{array}$ \\
\hline Wotherspoon et al. (17) & NISH (cell suspension) & 70 & LG & trisomy 3 in $60 \%$, trisomy 18 in $21 \%$ \\
\hline Wotherspoon et al. (18) & conventional cytogenetics & 23 & LG & trisomies $3,7,12,18$ in $22,17,13,9 \%$ \\
\hline
\end{tabular}

MALT, mucosa-associated lymphoid tissue; LG, low grade; HG, high grade; NISH, nonisotopic in situ hybridization; FISH, fluorescence in situ hybridization; CGH, comparative genomic hybridization; \#, chromosome. 

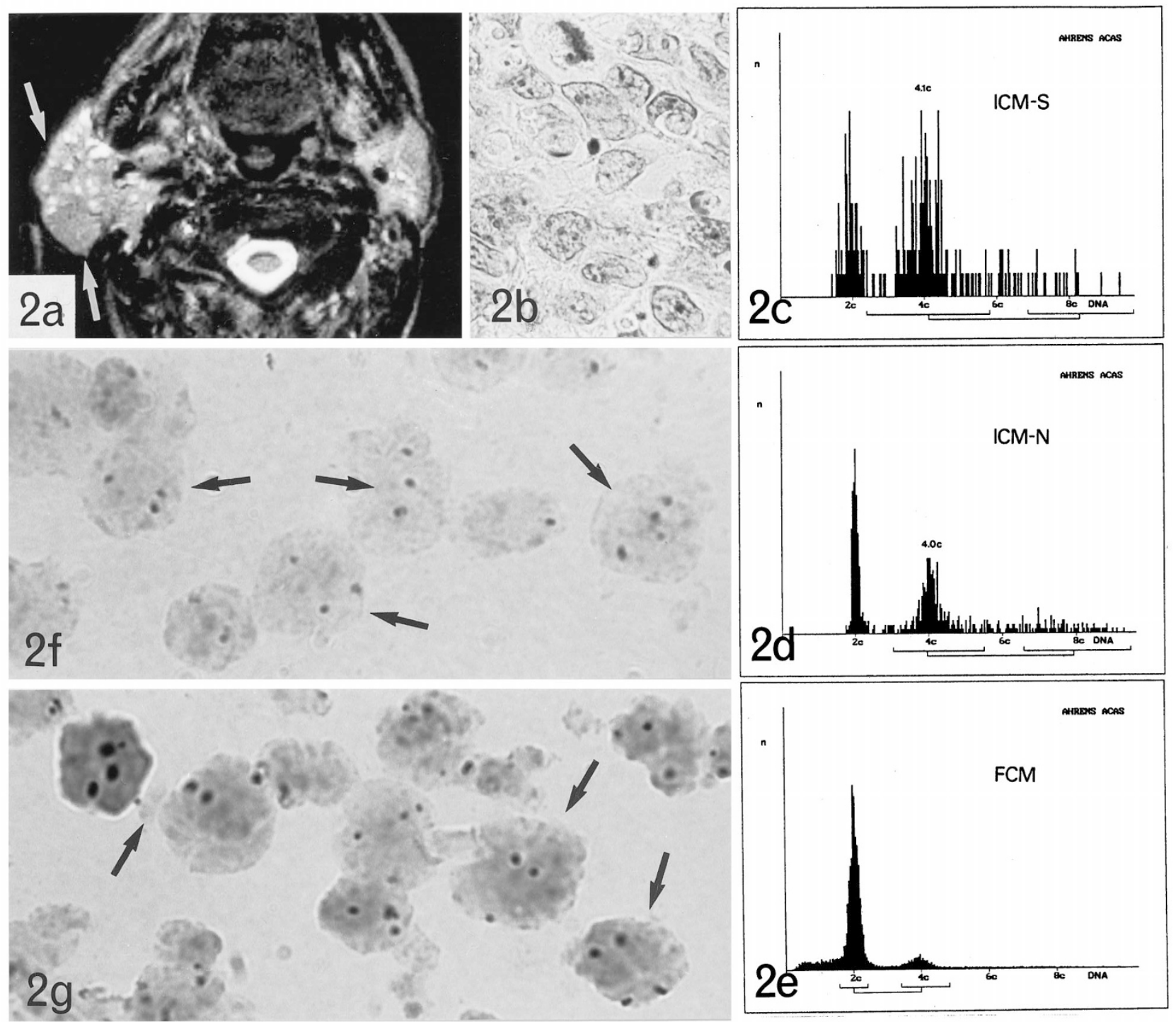

FIGURE 2. High-grade mucosa-associated lymphoid tissue (MALT)-type lymphoma (Case 29). a, in a transverse section of a T2-weighted magnetic resonance imaging study, the large tumor, confined to the right parotid gland and adjacent lymph nodes, exhibits typical radiologic features favoring MALT lymphoma (arrows; site of biopsy). Additional minor involvement of the left parotid gland is radiologically suspected (clinical stage IIE). b, in a Feulgen-stain, pleomorphic large nuclei of high-grade lymphoma are exhibited (original magnification, $450 \times$ ). c, the corresponding histogram of image cytometry of tissue section (ICM-S) with a nondiploid DNA content (4.1c; $\mathrm{CV}_{\text {diploid }}, 6.1 \%$; $\mathrm{CV}_{\text {nondiploid }}$, $8.8 \%$ ) is supported by image cytometry of nuclear suspension (ICM-N; 4.0c; $\mathrm{CV}_{\text {diploid }}, 4.8 \%$; $\mathrm{CV}_{\text {nondiploid }}, 7.7 \%$ ) (d). e, flow cytometry (FCM; $\mathrm{CV}_{\text {diploid }}, 4.7 \%$ ), however, proves not to be sensitive enough to detect the DNA nondiploid lymphoma cell population because of the abundant background of non-neoplastic cells. $\mathbf{f}, \mathbf{g}$, nonradiographic in situ hybridization of tissue sections (original magnification, 1200×) with centromere-specific probes for chromosomes 3 (f) and 18 (g) demonstrate complex chromosomal gains (arrows).

was incomplete or the follow-up period was short (6 patients). In one patient, transition of LG- to HG-MALT-L could be documented histologically; this was the only patient, as far as we know, who died of disseminated disease. Transformation of BLEL into LG-MALT-L was not seen in the patients with clinical follow-up.

\section{DNA (Flow and Image) Cytometry}

Ploidy data were gained by means of flow cytometry (FCM) and image cytometry (ICM), using Feulgen-stained tissue sections (ICM-S) and nuclear suspensions (ICM-N). For FCM and ICM-N analysis, any excess of normal tissue was removed from the paraffin blocks by dissection after comparison with adjacent hematoxylin-eosin sections. The nuclear preparation was performed after a modification of the method of Hedley et al. (25), as described by Baretton et al. (26). For ICM-S analysis, 6- to 8- $\mu \mathrm{m}$-thick sections were dewaxed in xylol and rehydrated. Afterward, sections-and also nuclear pellets from part of disintegrated tumor tissue (ICM-N)-were stained according to the Feulgen method $\left(5 \mathrm{n} \mathrm{HCl}\right.$ at $22^{\circ} \mathrm{C}$ for $55 \mathrm{~min}, 120 \mathrm{~min}$ Schiff's reagent, $3 \times 10 \mathrm{~min} \mathrm{SO}_{2}$ water). In five cases, only ICM could be performed because the remaining amount of tissue was too small for FCM. 
TABLE 2. Clinical Data und Results of Cytometrically Determinded DNA Ploidy Status and Interphase Cytogenetics in Cases of Sjögren/BLEL and of Low- and High-Grade MALT Lymphomas of Salivary Glands

\begin{tabular}{|c|c|c|c|c|c|c|c|c|c|c|c|c|c|}
\hline \multirow{2}{*}{ Case } & \multirow{2}{*}{ Diagnosis } & \multirow{2}{*}{$\begin{array}{l}\text { Sex/Age } \\
(\mathrm{yr})\end{array}$} & \multirow[t]{2}{*}{ Site } & \multirow[t]{2}{*}{ Stage $^{a}$} & \multicolumn{4}{|c|}{ DNA cytometry } & \multicolumn{5}{|c|}{$\begin{array}{c}\text { Interphase } \\
\text { cytogenetics/NISH }\end{array}$} \\
\hline & & & & & ICM-S (C) & ICM-N (C) & FCM (C) & Ploidy $^{b}$ & 3 & 7 & 12 & 18 & $\Sigma$ \\
\hline 1 & BLEL & $\mathrm{F} / 58$ & Paro & - & Di & Di & Di & Di & 0 & 0 & 0 & 0 & 0 \\
\hline 2 & BLEL & $\mathrm{F} / 67$ & Paro & - & Di & Di & Di & Di & 0 & 0 & 0 & 0 & 0 \\
\hline 3 & BLEL & $\mathrm{M} / 52$ & Paro & - & Di & Di & Di & Di & 0 & 0 & 0 & 0 & 0 \\
\hline 4 & BLEL & $\mathrm{F} / 39$ & Paro & - & $\mathrm{NE}$ & Di & Di & Di & $\mathrm{NE}$ & 0 & 0 & 0 & 0 \\
\hline 5 & BLEL & $\mathrm{F} / 65$ & Paro & - & Di & Di & Di & Di & 0 & 0 & 0 & 0 & 0 \\
\hline 6 & BLEL & $\mathrm{F} / 56$ & Paro & - & $\mathrm{NE}$ & Di & Di & Di & $\mathrm{NE}$ & 0 & 0 & 0 & 0 \\
\hline 7 & BLEL & $\mathrm{M} / 72$ & Paro & - & $\mathrm{Di}$ & Di & $\mathrm{Di}$ & $\mathrm{Di}$ & 0 & 0 & 0 & 0 & 0 \\
\hline 8 & BLEL & $\mathrm{F} / 59$ & Paro & - & Di & Di & Di & Di & 0 & 0 & 0 & 0 & 0 \\
\hline 9 & BLEL & $\mathrm{F} / 74$ & Paro & - & Di & Di & ND & Di & 0 & 0 & 0 & 0 & 0 \\
\hline 10 & BLEL & $\mathrm{F} / 75$ & Paro & - & $\mathrm{Di}$ & Di & ND & Di & 0 & 0 & 0 & 0 & 0 \\
\hline 11 & BLEL & $F / 71$ & Paro & - & Di & Di & ND & Di & $\mathrm{NE}$ & 0 & 0 & 0 & 0 \\
\hline 12 & BLEL & $\mathrm{F} / 45$ & Paro & - & Di & Di & Di & Di & $\mathrm{NE}$ & 0 & 0 & $\mathrm{NE}$ & 0 \\
\hline 13 & LG-MALT-L & $\mathrm{F} / 52$ & Paro & IE & Di & Di & $\mathrm{Di}$ & Di & 0 & 0 & 0 & + & 1 \\
\hline 14 & LG-MALT-L & $\mathrm{M} / 50$ & Sub & IE & Di & Di & Di & Di & 0 & 0 & + & 0 & 1 \\
\hline 15 & LG-MALT-L & $\mathrm{F} / 63$ & Lacr & IE & DI & Di & ND & Di & 0 & 0 & 0 & 0 & 0 \\
\hline 16 & LG-MALT-L & $\mathrm{F} / 59$ & Sub & IE & $\mathrm{Di}$ & Di & Di & Di & 0 & 0 & 0 & 0 & 0 \\
\hline 17 & LG-MALT-L & $\mathrm{F} / 34$ & Paro & IE & Di & Di & Di & Di & 0 & 0 & 0 & - & 1 \\
\hline 18 & LG-MALT-L & $\mathrm{F} / 78$ & Paro & IE & Di & Di & Di & Di & + & 0 & 0 & + & 2 \\
\hline 19 & LG-MALT-L & $\mathrm{F} / 74$ & Paro & IE & Di & Di & Di & Di & $\mathrm{NE}$ & 0 & 0 & + & 1 \\
\hline 20 & LG-MALT-L & $\mathrm{F} / 80$ & Paro & IE & $\mathrm{Di}$ & Di & Di & $\mathrm{Di}$ & $\mathrm{NE}$ & 0 & 0 & 0 & 0 \\
\hline 21 & LG-MALT-L & $\mathrm{F} / 69$ & Paro & IE & Di & Di & ND & Di & $\mathrm{NE}$ & 0 & 0 & + & 1 \\
\hline $22^{c}$ & LG-MALT-L & $\mathrm{M} / 69$ & Paro & IE & $\mathrm{Di}$ & ND & $\mathrm{Di}$ & Di & 0 & 0 & 0 & 0 & 0 \\
\hline $23^{c}$ & LG-MALT-L & $\mathrm{M} / 70$ & Sub & IIE & Di & Di & Di & $\mathrm{Di}$ & 0 & 0 & 0 & 0 & 0 \\
\hline 24 & LG-MALT-L & $F / 65$ & Paro & IE & Nondi (3.9) & Nondi (3.7) & Di & Nondi & + & + & + & + & 4 \\
\hline 25 & LG-MALT-L & $\mathrm{F} / 49$ & Paro & IE & Nondi (3.7) & Nondi (3.9) & Di & Nondi & + & + & + & + & 4 \\
\hline 26 & HG-MALT-L & $\mathrm{F} / 76$ & Paro & IE & $\mathrm{Di}$ & Di & $\mathrm{NE}$ & Di & 0 & 0 & + & 0 & 1 \\
\hline $27^{c}$ & HG-MALT-L & $\mathrm{M} / 72$ & Sub & IIE & Nondi (3.9) & Nondi (4.1) & Nondi (4.2) & Nondi & + & + & + & + & 4 \\
\hline 28 & HG-MALT-L & $\mathrm{F} / 75$ & Paro & IE & Nondi (3.5) & Nondi (3.6) & $\mathrm{Di}$ & Nondi & $\mathrm{NE}$ & + & + & + & 3 \\
\hline 29 & HG-MALT-L & $\mathrm{M} / 69$ & Paro & IIE & Nondi (4.1) & Nondi (4.0) & Di & Nondi & + & + & + & + & 4 \\
\hline
\end{tabular}

BLEL, benign lymphoepithelial lesion; MALT, mucosa-associated lymphoid tissue; NISH, nonisotopic in situ hybridization ( $0=$ no aberration); ICM-S, image cytometry using tissue sections; ICM-N, image cytometry using nuclear suspension; FCM, flow cytometry; (C), c value of DNA nondiploid stem lines (diploid $=2.0$ ); F, female; M, male; Paro, parotid gland; Sub, submandibular gland; Lacr, lacrimal gland; Di, diploid, NE, not evaluable; Nondi, nondiploid; ND, not done; +, chromosomal gain; -, chromosomal loss; $\Sigma$, sum of numeric chromosomal aberrations.

${ }^{a}$ According to Isaacson (2).

${ }^{b}$ Determined by ICM-S and ICM-N.

${ }^{c}$ Patient with follow-up biopsies 1 and 3 years after initial biopsy.

Only FCM histograms with a coefficient of variation value of the diploid peak less than $7.5 \%$ were accepted (27). DNA nondiploidy was diagnosed in FCM when a histogram revealed more than one identifiable cell population. Cases with DNA index values between $3.8 \mathrm{c}$ and $4.2 \mathrm{c}$ were classified as tetraploid if more than $20 \%$ of the impulses were registered in this range and a G2/M peak was identifiable between 7.6c and 8.4c (28). For ICM-S and ICM-N measurements, a PC-based image analyzer ACAS (Ahrens, Bargteheide, Germany) composed of a special software ACAS 4 (Ahrens) and a Laborlux S microscope (Leitz, Wetzlar, Germany) was used. For assessment of the diploid range (2.0c), the integrated absorbance of the nuclei of 25 to 30 granulocytes was measured (27). For the ICM-S analysis in hematoxylin-eosin-stained sections, manifest lymphoma areas or reactive lymphoid tissue (BLEL) were identified in the respective periductal areas. Subsequently, 150 to 250 nonoverlapping nuclei were measured in the corresponding regions of Feulgen-stained serial sections. In two cases, ICM-S was not evaluable because of intense nuclear overlapping. According to the literature, DNA nondip- loidy was assumed when stem line ploidy was $2.4 \mathrm{c}$ or more; more than $45 \%$ of nuclei exhibited a DNA content $2.5 \mathrm{c}$ or more (26). We are aware that in tissue sections, a varying portion of the nucleus is present, depending on the section thickness and nuclear size $(27,29)$. This shortcoming of ICM-S was to be overcome by combination with ICM-N, where a selective measurement of intact, nonoverlapping nuclei with cytologic characteristics of the relevant lymphoma population enabled an exact determination of a putative aberrant stem line. Because of the lack of histomorphologic correlation in ICM-N, nondiploidy was diagnosed only when a comparable stem line was demonstrated in ICM-S. Altogether, cases were classified as DNA nondiploid when an abnormal DNA content was revealed by FCM or ICM or by both methods.

\section{Interphase Cytogenetics/Nonisotopic In Situ Hybridization}

Because conventional cytogenetic studies have shown most numeric aberrations for the chromosomes $3,7,12$, and $18(7,8,18,29)$, for the NISH 
investigation we used commercial biotinylated DNA probes binding to highly repetitive alphoid DNA located at the centromeres of chromosomes 7 (D7Z1), 12 (D12Z1), and 18 (D18Z1; ONCOR, Amersham Buchler, Gaithersburg, MD). A probe of chromosome 3 ( $P$ alpha 3.5) was provided by $G$. Sauter, M.D. (Basel, Switzerland). NISH was performed after a protocol according to Hopman et al. (30) with our own modifications $(26,29)$. Digestion times were evaluated for each case, ranging from 0 to $2 \mathrm{~min}$. Hybridization signals were enumerated in 200 to 300 interphase nuclei in the regions of interest, described above. Capping of nuclei in sections can result in underestimating the real chromosomal copy number. To rule out methodological artifacts, all nuclei in well-reacting areas were analyzed, including those without any NISH signal. To ensure that the tissue has been adequately digested, the number of nuclei without any signal should not exceed $15 \%$, with the exception of cases of partial monosomy. The total percentage of nuclei containing no, 1, 2, 3, 4, and so forth NISH signals per nucleus was determined for each DNA probe. Overlapping nuclei and minor hybridization spots were not counted; spots in paired arrangement (split spots) were counted as one signal $(29,30)$. According to recent investigations of our group in prostate cancer and abortion tissue $(26,29)$, a deletion was diagnosed when more than $40 \%$ of the nuclei showed only one or no signal; chromosomal gain was assumed when more than $15 \%$ of nuclei exhibited three or more signals.

\section{RESULTS}

\section{Cytometric Ploidy Status}

All 12 cases of BLEL, 11 of 13 cases of LGMALT-L, and 1 of 4 cases of HG-MALT-L were DNA diploid (Figs. 1c, d), whereas 3 of 4 cases of HG- and 2 of 13 cases of LG-MALT-L were DNA nondiploid in both ICM-S and ICM-N (Figs. 2c, d), all demon- strating peritetraploid stem lines (3.6c to 4.1c) with a maximum difference between corresponding $\mathrm{c}$ values of $0.3 \mathrm{c}$. In the FCM analysis, 22 of 23 cases, evaluable, proved to be DNA diploid (Figs. 1e, 2e); only one of five lymphomas with aberrant stem lines in ICM techniques proved to be DNA nondiploid in FCM analysis as well. Taking into account all three DNA cytometric techniques, 3 of 4 HG- and 2 of 13 LG-MALT-L were DNA nondiploid.

\section{$\mathrm{NISH}$}

We evaluated 107 of 116 (92.2\%) in situ hybridization reactions, which were performed using four centromere-specific probes (\#3, 7, 12, 18), on the 29 cases investigated. No BLEL cases, 8 of 13 LGMALT-L cases, and all 4 HG-MALT-L cases demonstrated numeric chromosomal aberrations. With the exception of one case with loss of one copy of \#18, all cases exhibited chromosomal gain. LGMALT-L were associated with trisomies $3,7,12$, and 18 in $30,15,23$, and $46 \%$ of the cases, respectively. Three of four HG-MALT-L were characterized by gains of all four chromosomes tested, whereas one of four demonstrated gain of \#12 only.

\section{Correlation of Ploidy Status and NISH Results}

The 5 DNA nondiploid lymphomas (3 of 4 HGand 2 of 13 LG-MALT-L), all with peritetraploid stem lines, demonstrated gains in NISH signal numbers for all chromosomes tested (Figs. 2f, g). Seventeen of the 24 DNA-diploid cases (12 of 12 BLEL, 5 of 13 LG-MALT-L) were free of numeric aberrations for the four centromere probes tested, whereas 7 cases (6 of 13 LG- and 1of 4 HG-MALT-L) demonstrated one or two numeric chromosomal aberrations (Figs. 1f, g). In the 11 DNA-diploid LGMALT-L, mostly single numeric gains could be demonstrated for \#18 (4 of 11 [36\%]), followed by \#3 (1 of $8[12 \%]$ ) and \#12 (1 of 11 [9\%]; see also Tables 2 and 3$)$.

TABLE 3. Correlation of Ploidy (DNA Cytometry) and Numeric Chromosomal Aberrations (NISH)

\begin{tabular}{|c|c|c|c|c|}
\hline \multirow[b]{2}{*}{ Diagnosis } & \multirow{2}{*}{$\begin{array}{l}\text { No. } \\
\text { cases }\end{array}$} & \multirow{2}{*}{$\begin{array}{l}\text { DNA cytometry } \\
\text { (ploidy [c]) }\end{array}$} & \multicolumn{2}{|c|}{ Interphase Cytogenetics/NISH } \\
\hline & & & Chromosomal status & $\begin{array}{l}\text { Number and type of numeric } \\
\text { chromosomal aberrations }(\# 3,7,12,18)\end{array}$ \\
\hline BLEL & 12 & 12/12 DNA diploidy & 12/12 disomy & - \\
\hline LG-MALT-L & 13 & 11/13 DNA diploidy & $\begin{array}{l}\text { 5/11 disomy } \\
6 / 11 \text { aneusomy }\end{array}$ & $\begin{array}{l}- \\
\text { Gain of } \# 18 \text { ( } 3 \text { cases }) \text { or of \#12 (1 case) } \\
\text { Gain of \#3 } 18 \text { ( } 1 \text { case }) \\
\text { Loss of \#18 (1 case) }\end{array}$ \\
\hline & & $\begin{array}{l}\text { 2/13 DNA nondiploidy } \\
(3.7 ; 3.9)\end{array}$ & $2 / 2$ aneusomy & Gain of all chromosomes tested \\
\hline HG-MALT-L & 4 & $\begin{array}{l}\text { 1/4 DNA diploidy } \\
\text { 3/4 DNA nondiploidy } \\
(3.6 ; 4.0 ; 4.1)\end{array}$ & $\begin{array}{l}1 / 1 \text { aneusomy } \\
3 / 3 \text { aneusomy }\end{array}$ & $\begin{array}{l}\text { Gain of \#12 ( } 1 \text { case) } \\
\text { Gain of all chromosomes tested }\end{array}$ \\
\hline
\end{tabular}

NISH, nonisotopic in situ hybridization; c, c value of DNA nondiploid stem line according to image cytometry with nuclear suspension (diploid $=2.0$ ); BLEL, benign lymphoepithelial lesion; LG-MALT-L, low grade mucosa-associated lymphoid tissue-type lymphoma; HG-MALT-L, high grade mucosaassociated lymphoid tissue-type lymphoma; \#, chromosome. 


\section{DISCUSSION}

The genetic mechanisms that lead to extranodal marginal zone B-cell lymphoma of MALT type are still poorly understood. Molecular genetic studies have been unable to demonstrate a consistent cytogenetic abnormality; trisomy 3 and translocation $(11 ; 18)(\mathrm{q} 21 ; \mathrm{q} 21)$ have been implicated by some authors in the development of LG-MALT-L. These cytogenetic data were gathered mainly in gastric tumors $(16,18-23,31,32)$, whereas only few salivary gland MALT lymphomas have been investigated by conventional and interphase cytogenetics $(16,17,19,23,24)$ (Table 1). In the present study of the largest series of salivary gland MALT lymphomas to date, we tried to achieve a better comprehension of related cytogenetic alterations by correlating DNA ploidy and numeric chromosomal aberrations, assessed by DNA cytometry and interphase cytogenetics, including cases of BLEL.

To the best of our knowledge, no data are available on DNA ploidy in salivary gland MALT lymphomas. Comparing BLEL with LG- and HGMALT-L, we found an increasing rate of DNA nondiploidy: Whereas all cases of BLEL proved to be DNA diploid, we found a peritetraploid DNA distribution in 3 of 4 HG- and 2 of 13 LG-MALT-L. As discussed earlier, we performed ICM-S of tissue sections preferentially, bearing in mind that quantitative measurements of sections are hampered by a certain degree of nuclear overlapping and truncation of nuclei $(27,29)$. In additionally performed ICM-N, all aberrant stem lines of ICM-S could be verified (Figs. 1c, d, 2c, d). Moreover, DNA nondiploidy in ICM could be substantiated in all five cases by the evidence of complex chromosomal gains in the NISH technique. In comparison, the sensitivity of FCM clearly was lower: In only one of five aberrant cases, DNA nondiploidy was detected in FCM analysis as well. This presumably is due to the high number of reactive cells in nuclear suspensions used for FCM analysis. As no direct histo- or cytomorphologic control is possible in this approach, small aberrant cell clones can be masked within the abundant background of non-neoplastic cells in the FCM histograms (28) (Figs. 2c-e). Thus, a comparison of the different DNA cytometric techniques, as well as earlier results by our group $(27,29)$, supports an approach to use tissue sections for the determination of the nuclear DNA content.

As we have found a peritetraploid DNA nondiploidy in three of four cases of HG-MALT-L, doubling of the total chromosomal number might be an important step in the progression to high-grade tumors of salivary glands. This is underlined by a conventional cytogenetic study by Ott et al. (16), in which a doubling of chromosomal number was detected in 3 of 24 HG-MALT-L of different localiza- tions, manifesting in only 1 of 19 gastric but in 2 of 4 salivary gland tumors (Table 1). In comparison, in nodal-type NHL, a frequency of DNA nondiploidy is reported in 7 to $30 \%$ of low-grade and 30 to $80 \%$ of high-grade tumors $(33,34)$. Although only a small number of HG-MALT-L of salivary glands have been investigated and a comparison of the different techniques is difficult, our results and the findings by Ott et al. (16) indicate that a peritetraploid DNA distribution might be a prevalent feature of HGMALT-L of the salivary glands, but probably not of the stomach or of other sites. Further investigations of more cases are required to prove this hypothesis.

As we have detected a peritetraploid DNA distribution also in 2 of 13 LG-MALT-L, determination of DNA ploidy does not allow a clear-cut distinction between LG- and HG-MALT-L of salivary glands. Regarding the 11 DNA-diploid LG-MALT-L, we found gain or loss of one or two chromosomes in 6 of 11 cases, applying NISH analysis. Thereby, trisomies 18,3 , and 12 were detected in 36,12 , and $9 \%$ of the cases, respectively. These findings are in contrast to a NISH study of cell suspensions by Wotherspoon et al. (17), who found trisomy 3 in $82 \%$ of LG-MALT-L of salivary glands, whereas Ott et al. (16) in conventional cytogenetics did not find a consistent aberration in four low-grade tumors (Table 1). Possible underlying molecular mechanisms by which trisomy 18 or 3 might contribute to the pathogenesis of LG-MALT-L of salivary gland remain speculative at this stage. The limited follow-up data of the present study do not allow a prognostic evaluation of the cytogenetic findings.

Taking into account MALT lymphomas of all locations, cytogenetic data proved to be even more diverse. Some authors found a high rate of trisomy 3 in LG-MALT-L of all sites $(17,18,31)$; others (16) described a high rate of $t(11 ; 18)(q 21 ; q 21)$. Studies on HG-MALT-L showed gain of part or all of \#12 or $\# 11$ and 12 , respectively $(21,22)$ (summarized in Table 1). Apart from differing lymphoma localization, these cytogenetic discrepancies might be the result of methodological differences in the techniques applied: MALT lymphomas are characterized by a high degree of admixture of reactive lymphoid parenchyma and residual epithelial and stromal cells. As cell suspensions usually have been applied, an obstacle of studies that use conventional cytogenetics is the lack of a direct histomorphologic correlation and, hence, probably limited sensitivity $(26,29)$. Furthermore, DNA nondiploidy or complex chromosomal gains, respectively, can reliably be detected only by DNA cytometry or conventional cytogenetics. In this respect, a major advantage of our approach was that two methodologically different techniques were combined and were applied preferentially on paraffin sections, enabling each a reliable measurement of histomorphologi- 
cally verified regions of interest. The documented good accordance among ICM-S, ICM-N, and NISH, as well as recent studies by our group $(26,27,29)$, demonstrates the validity of this approach.

In summary, the comparison of cytogenetic findings in Sjögren's syndrome/BLEL and LG- and HGMALT-L of salivary glands demonstrated a progressive increase in frequency and number of cytogenetic abnormalities: Whereas cases of BLEL showed abnormal findings neither in DNA cytometry nor in NISH, the majority of LG-MALT-L demonstrated single numeric chromosomal aberrations in NISH. Thereby, a possible implication of trisomy 18 for the progression of low-grade marginal zone B-cell lymphomas of salivary glands is indicated, whereas the postulated role of trisomy 3 could not be verified. Conversely, few LG- and most HGMALT-L were characterized by a peritetraploid DNA distribution with complex chromosomal gains in NISH, indicating that doubling of the total chromosomal number might be an important step in the further progression to salivary gland HGMALT-L. However, from a diagnostic point of view, our cytogenetic findings do not allow a clear-cut distinction among BLEL, LG-MALT-L, and HGMALT-L of salivary glands.

Acknowledgments: The authors thank Natalie Rademacher for the excellent technical assistance in the laboratory work and Monika Attmanspacher for the skillful preparation of the figures.

\section{REFERENCES}

1. Ellis GL, Auclair PL. Malignant lymphomas of the major salivary glands. In: Ellis GL, Auclair PL, editors. Atlas of tumor pathology. Tumors of the salivary glands. Washington, DC: Armed Forces Institute of Pathology; 1996. pp. 387-402.

2. Isaacson PG. Malignant lymphoma of the salivary glands. In: Isaacson PG, Norton AJ, editors. Extranodal lymphomas. Edinburgh, Great Britain: Churchill Livingstone; 1994. pp. 67-83.

3. Harris NL, Jaffe ES, Stein H, Banks PM, Chan JKC, Cleary ML, et al. A revised European-American classification of lymphoid neoplasms: a proposal from the International Lymphoma Study Group. Blood 1994;84:1361-92.

4. Hyjek E, Smith WJ, Isaacson PG. Primary B-cell lymphoma of salivary glands and its relationship to myoepithelial sialadenitis. Hum Pathol 1988;19:766-76.

5. Schmid U, Lennert K, Gloor F. Immunosialadenitis (Sjögren's syndrome) and lymphoproliferation. Clin Exp Rheumatol 1989;7:145-80.

6. Grevers G, Ihrler S, Vogl TJ, Weiss M. A comparison of clinical, pathological and radiological findings with magnetic resonance imaging studies of lymphomas in patients with Sjögren's syndrome. Eur Arch Otorhinolaryngol 1994; 251:214-7.

7. Bateman AC, Wright DH. Epitheliotropism in high-grade lymphomas of mucosa-associated lymphoid tissue. Histopathology 1993;23:409-15.

8. Falzon M, Isaacson PG. The natural history of benign lym- phoepithelial lesion of the salivary gland in which there is a monoclonal population of B cells. Am J Surg Pathol 1991;15: $59-65$.

9. Müller-Hermelink HK, Greiner A. Autoimmune diseases and malignant lymphoma. Verh Dtsch Ges Path 1992;76:96-109.

10. Heckmayr M, Seifert G, Donath K. Maligne lymphome und immunsialadenitis. Laryng Rhinol 1976;55:593-607.

11. Ihrler S, Zietz C, Riederer A, Diebold J, Löhrs U. HIV-related parotid lymphoepithelial cysts: immunohistochemistry and 3-D reconstruction of surgical and autopsy material with special reference to formal pathogenesis. Virchows Arch 1996;429:139-47.

12. Ihrler S, Zietz C, Sendelhofert A, Riederer A, Löhrs U. Lymphoepithelial duct lesions in Sjögren-type sialadenitis. Virchows Arch 1999;434:315-23.

13. Burke JS. Are there site-specific differences among the MALT lymphomas-morphologic, clinical? Am J Clin Pathol 1999; 111(Suppl. 1):133-43.

14. Kurtin PJ. How do you distinguish benign from malignant extranodal small B-cell proliferations? Am J Clin Pathol 1999; 111(Suppl. 1):119-26.

15. Quintana PG, Kapadia SB, Bahler DW, Johnson JT, Swerdlow SH. Salivary gland lymphoid infiltrates associated with lymphoepithelial lesions: a clinicopathologic, immunophenotypic, and genotypic study. Hum Pathol 1997;28:850-61.

16. Ott G, Katzenberger T, Greiner A, Kalla J, Rosenwald A, Heinrich $U$, et al. The $\mathrm{t}(11 ; 18)(\mathrm{q} 21 ; \mathrm{q} 21)$ chromosome translocation is a frequent and specific aberration in low-grade but not high-grade malignant non-Hodgkin's lymphomas of the mucosa-associated lymphoid tissue (MALT)-type. Cancer Res 1997;57:3944-8.

17. Wotherspoon AC, Finn TM, Isaacson PG. Trisomy 3 in lowgrade B-cell lymphomas of mucosa-associated lymphoid tissue. Blood 1995;85:2000-4.

18. Wotherspoon AC, Pan L, Diss TC, Isaacson PG. Cytogenetic study of B-cell lymphoma of mucosa-associated lymphoid tissue. Cancer Genet Cytogenet 1992;58:35-8.

19. Ott G, Kalla J, Steinhoff A, Rosenwald A, Katzenberger T, Roblick U, et al. Trisomy 3 is not a common feature in malignant lymphomas of mucosa-associated lymphoid tissue type. Am J Pathol 1998;153:689-94.

20. Clark HM, Jones DB, Wright DH. Cytogenetic and molecular studies of $\mathrm{t}(14 ; 18)$ and $\mathrm{t}(14 ; 19)$ in nodal and extranodal B-cell lymphoma. J Pathol 1992;166:129-37.

21. Chan W-Y, Wong Nathalie, Chan AB, Chow JH, Lee JC. Consistent copy number gain in chromosome 12 in primary diffuse large cell lymphomas of the stomach. Am J Pathol 1998;152:11-6.

22. Barth TFE, Döhner H, Werner CA, Stilgenbauer S, Schlotter M, Pawlita M, et al. Characteristic pattern of chromosomal gains and losses in primary large B-cell lymphomas of the gastrointestinal tract. Blood 1998;91:4321-30.

23. Whang-Peng J, Knutsen T, Jaffe E, Raffeld M, Zhao WP, Duffey $\mathrm{P}$, et al. Cytogenetic study of two cases with lymphoma of mucosa-associated lymphoid tissue. Cancer Genet Cytogenet 1994;77:74-80.

24. Auer IA, Gascoyne RD, Connors JM, Cotter FE, Greiner TC, Sanger WG, et al. T(11;18)(q21;q21) is the most common translocation in MALT lymphomas. Ann Oncol 1997;8:97985.

25. Hedley DW, Friedlander ML, Taylor IW, Rugg CA, Musgrove EA. Method for analysis of cellular DNA-content of paraffinembedded pathological material using flow cytometry. J Histochem Cytochem 1983;31:1333-5.

26. Baretton GB, Valina C, Vogt T, Schneiderbanger K, Diebold J, Löhrs U. Interphase cytogenetic analysis of prostatic carcinomas by use of nonisotopic in situ hybridization. Cancer Res 1994;54:4472-80.

27. Baretton GB, Blasenbreu S, Li X, DePascale T, Löhrs U. 
DNA-cytometry using routinely formalin-fixed and paraffinembedded tumour tissue: a comparative study by means of flow (FCM) and image (ICM) cytometry. Zentralbl Pathol 1993;139:14-20.

28. Koss LG, Czerniak B, Herz F, Wersto RP. Flow cytometric measurements of DNA and other cell components in human tumors. Hum Pathol 1989;20:528-48.

29. Baretton GB, Müller M, Wirtz A, Murken J, Arnholdt H. Numerical chromosomal aberrations in abortion tissues: comparison of conventional and interphase cytogenetics in paraffin sections and nuclear suspensions. Pathologe 1998; 19:120-8.

30. Hopman AH, van Hooren E, van de Kaa CA, Vooijs PG, Ramaekers FC. Detection of numerical chromosomal aberrations using in situ hybridization in paraffin sections of routinely processed bladder cancers. Mod Pathol 1991;4:
503-13.

31. Dierlamm J, Michaux L, Wlodarska I, Pittaluga S, Zeller W, Stul M, et al. Trisomy 3 in marginal zone B-cell lymphoma: a study based on cytogenetic analysis and fluorescence in situ hybridization. Br J Haematol 1996;93:242-9.

32. Brynes RK, Almaguer PD, Leathery KE, McCourty A, Arber DA, Medeiros LJ, et al. Numerical cytogenetic abnormalities of chromosomes 3, 7, and 12 in marginal zone B-cell lymphomas. Mod Pathol 1996;9:995-1000.

33. Macartney JC, Camplejohn RS. DNA flow cytometry of nonHodgkin's lymphomas. Eur J Cancer 1990;26:635-7.

34. Cavalli C, Danova M, Gobbi PG, Riccardi A, Magrini U, Mazzini G, et al. Ploidy and proliferative activity measurement by flow cytometry in non-Hodgkin's lymphomas: do speculative aspects prevail over clinical ones? Eur J Cancer Clin Oncol 1989;25:1755-63.

\section{Book Review}

\section{Geisinger KR, Silverman JF: Fine Needle Aspi- ration Cytology of Superficial Organs and Body Sites, 221 pp, New York, Churchill Livingstone, 1999 (\$175).}

In the preface, the authors emphasize a practical approach to fine needle aspiration biopsies that is suitable for both the inexperienced and the seasoned pathologist. The histopathologic concepts responsible for specific cytomorphologic details are addressed in a concise, practical fashion using current terminology supported by high quality color images and charts.

The authors, along with a host of experienced contributors, have recognized the increasing popularity of fine needle aspiration biopsies and have succeeded in presenting a systemic account of their combined "practical expertise." This comprehensive collaboration adheres to the philosophy of the integrated diagnostic approach, using fine needle aspiration as both diagnostic and supportive, depending on the situation.

The target audience is the practicing pathologist; however, students, residents, fellows, and practitioners alike will find this volume useful. Compiled by two recognized experts in the field, this work is a welcome addition to any library.

The text is organized into six basic chapters encompassing the type of specimens one would expect to encounter in day-to-day practice: lymph node, breast, salivary gland and head and neck, thyroid, skin, and soft tissue. Each respective area is well covered, combining text and color images. Short bulleted lists of pertinent cytomorphologic features enhance most of the sections, providing a handy reference for "quick look" diagnoses. The chapters on lymph node and on salivary gland and head and neck were particularly well presented, offering extensive coverage of both benign and malignant lesions. The inclusion of ancillary test results such as flow cytograms and immunophenotypic data gives the color images more impact, leaving the reader with enough information to render a quick and accurate diagnosis for lymphoid lesions. Likewise, the salivary gland and head and neck chapter was current and complete, containing a nice preface on anatomic and clinical considerations, cytodiagnostic problems related to fine needle aspiration in this area, and clinical expectations. The easy-to-read tables conveyed the most important diagnostic details and differential diagnoses for salivary gland lesions seen commonly in general practice.

Although there are larger texts available that adequately cover fine needle aspiration cytology, few present this amount of information in such a practical manner. The text reads well, and the quality and number of color images will please readers at all levels of expertise. I recommend this text for anyone involved with fine needle aspiration of superficial body sites. Residents, fellows, and practicing pathologists will be impressed with this comprehensive, practical book.

\section{Paul Munyer \\ University of Kansas Medical Center Kansas City, Kansas}

